\title{
Microwave Thermotherapy
}

National Cancer Institute

\section{Source}

National Cancer Institute. Microwave Thermotherapy. NCI Thesaurus. Code C93351.

Any procedure in which microwave irradiation is used for the purpose of heating and destroying the surrounding tissue. 